\title{
Grandparents in Italy: trends and changes in the demography of grandparenthood from 1998 to 2016
}

\author{
Elisa Cisotto ${ }^{1}$, Eleonora Meli $^{2}$, Giulia Cavrini ${ }^{1}$ \\ ${ }^{1}$ Free University of Bozen-Bolzano \\ ${ }^{2}$ Italian National Institute of Statistics, ISTAT
}

\begin{abstract}
In this article we explore the last two decades of changes in the demography of grandparenthood in Italy, by means of a set of measures: the proportion of men and women becoming grandparents by age and time, the age at transition to grandparenthood and its crossing with a set of life events and the length of grandparenthood. We used data from the four waves of the Survey on Family and Social Subjects carried out by the Italian National Institute of Statistics in 1998, 2003, 2009 and 2016. Overall, the median age at which half of the population over 35 is made up of grandparents moved forward by at least 5 years during the two observed decades. The postponement of grandparenthood is evident in middle age: between 55 and 64 the ratio of grandparents to non-grandparents decreased significantly by about 10 per cent. Overall, among people who had ever had children, the median age at the transition to grandparenthood advanced by three years from 1998 to 2016, both for men (59 to 62) and women (54 to 57). This difference is greater than that observed for age at parenthood and equal to the advantage gained in terms of life expectancy at age 60. Thus, although grandparenthood has been postponed over the last two decades in Italy, the great gains in remaining life expectancy result in grandparent-grandchildren lifetime not being reduced.
\end{abstract}

\section{Keywords}

Grandparenthood, grandparents, Italy, demography, age at grandparenthood, trends 


\section{Introduction}

During the twentieth century, a twofold demographic revolution took place in all Western countries. On the one side, an exceptional increase in life expectancy and, from the second half of the century, a sharp decline in fertility. These demographic changes have led to a rapidly ageing population, involving the time period that individuals spend in different family roles, marking the onset and duration of intergenerational relationships. Of those, one of the most affected is grandparenthood. Increased life expectancy adds years to the time spent as a grandparent, while fertility postponement defers the transition to grandparenthood and increasing childlessness rises the share of people who never become grandparents.

In this article, we examine changes over an 18-year period of grandparenthood in Italy by considering a set of measurements which are grandparents' demographic and socioeconomic characteristics, number of grandchildren, grandparenthood prevalence, timing of grandparenthood and its life course context.

On a background level, Italy is a country which since the second half of the twentieth century has experienced a steeper decline in mortality and fertility compared to other developed countries. According to the latest available data (ISTAT 2021), life expectancy at birth reached 81 years for men and 85 for women in 2019. The total fertility rate (TFR) has declined throughout the twentieth century from 2.3 children per woman in 1952 to 1.3 children per woman in 2019, and the average age at first child for women increased from 25 to 32 in the same period of time. Furthermore, Italy is an informative country to study the transition to grandparenthood over time due to its family-focused societal context, and the central role that grandparents play in providing informal childcare (Glaser and Hank 2018; Zamberletti, Cavrini, and Tomassini 2018).

However, little is known on how the grandparent phase of life is changing in Italy, and the demography of Italian grandparenthood is only being studied to a limited extent. In this work, we exploit individual-level information from an ISTAT series of Italian surveys on families carried out in Italy in 1998, 2003, 2009 and 2016. Thus, we add to the existing knowledge in relation to the national context by exploring the demography of Italian grandparenthood from a time-based comparative approach. 
The paper is structured as follows. We begin by introducing the basic background. We see grandparenthood as a key event in the transition to older age, and we outline the possible changes one can expect according to the demographic dynamics of the last two decades. Then we review some previous studies and briefly discuss relevant findings and key patterns. In the next section, the data and methods we used are introduced and results are

presented. First, we give extensive descriptive statistics displaying the evolution of the main demographic and socio-economic characteristics of grandparents. Second, following Margolis (2016), we analyse changes in the proportion of adults with grandchildren, with children but no grandchildren and childless from 1998 to 2016, to disentangle the extent and causes of grandparenthood delay. According to Leopold and Skopek (2015) then we explore the median age at transition to grandparenthood, its interconnections with other life events, and its duration. This is followed by a discussion and conclusions.

\section{Background}

We know relatively little about grandparents, almost nothing about grandparents in the past, and little more about grandparents now. The gap in research on grandparents in the past is partly explained by the focus of family studies on the existence of the so-called nuclear family, isolated from kinship, theorized by Talcott Parsons as an emerging functional model for the needs of the western industrialized society (Zanatta 2013). Furthermore, until the recent past, the image of grandparents in Western societies was associated with old age and physical decline, and the high mortality rate for older people very often prevented the creation and strengthening of the relationship between grandparents and grandchildren. Since the second half of the twentieth century, there has been a real revolution in this respect. Life expectancy has lengthened, and what we now call 'the third age' has emerged, in which older people are in good health, have become economically independent, can engage in activities, and interact with the younger generations. From the second half of the century, the sharp fertility decline has also led to the establishment of more intense and personalised intergenerational relationships as multiple generations in a family spend more of their years together than ever before (Bengtson 2001; Lesthaeghe 2010). 
In the context of the growing relevance of multigenerational family relationships, intergenerational relations between grandparents and their grandchildren have been recognized as one of the most common and significant multigenerational ties (Silverstein, Giarrusso, and Bengtson 1998; Uhlenberg 1993), and research on ageing families and grandparenthood has broadened in recent decades, both in a number of European countries and internationally (Hank et al. 2018). Most of these deal with the grandparental role in childcare and family support, while occasionally, research has referred to the changing demography of the grandparent-grandchild relationship. This is particularly the case in the European context as empirical evidence on this issue mainly focuses on North America (Skopek 2021).

The demography of grandparenthood concerns the impact of demographic changes on grandparenthood, such as mortality reduction and changes in fertility behaviours. It addresses a set of questions. For example, at what age is grandparenthood mostly occurring? How much of their lifetime do grandparents spend with their grandchildren? Has it increased over time?

Szinovacz (1998) was among the first to employ survey data to provide answers to some of these questions, providing results for the timing of the transition to grandparenthood in the United States. Based on the National Survey of Families in Households, she estimated that the mean age at grandparenthood in 1990 was 46 for women and 49 for men. Following Szinovacz's approach, later estimates came for Canada (Kemp 2003) and the Netherlands (Dykstra and Komter 2006).

One special comprehensive analysis of the timing of grandparenthood is given by Leopold and Skopek (2015) using data from the USA and Europe (Italy not included). In their international comparison study, they first state considerable heterogeneity across countries in the median age at grandparenthood for grandparents born between about 1930 and 1947. Second, they provide evidence of cross-national disparities in the life course context in which the transition to grandparenthood is experienced. Third, by taking the difference between life expectancy at age 60 and the median age at grandparenthood, they show substantial variation across countries in the length of grandparents' stage of life. Further, using data from the German Ageing Study, Leopold and Skopek (2015a) compares German women born between 1949-1958 and 1929-1938 to analyse cohort changes in grandparenthood 
transition. Their results reveal a substantial delay in the timing of grandparenthood over the observed 20 years. Further to this, they find a strong educational gradient in the probability of grandparenthood among West German women born between 1933-1948 (Skopek and Leopold 2017). Using simulated data, Margolis and Verdery (2019) estimated the historical changes in the demography of grandparenthood in the United States for the 1880-1960 birth cohorts, confirming an increase in the median age of grandparenthood.

Using Canadian data from 1985 to 2011, Margolis (2016) also finds a general postponement of grandparenthood status in the population, with an increase of about 10 years in the median age at grand-motherhood. Nevertheless, the delayed timing of grandparenthood does not shorten the length of life lived as grandparent in Canada, as it is offset by an increase in life expectancy. Furthermore, evidence confirms that the period of healthy grandparenthood in the USA and Canada is becoming longer because of improvements in health and mortality, which more than compensates delays in grandparenthood (Goodman, Keyfitz, and Pullum 1974; Margolis and Iciaszczyk 2015; Margolis and Wright 2017; Song and Mare 2019).

The available evidence suggests that there have been significant changes in the demographic trends in grandparenthood. However, European evidence is still fragmented. Based on Finnish church records, Chapman et al. (2017) analysed changes in the length of grandparenthood from 1790 to 1959, reporting a considerable increase in the number of years of life shared by grandparents and grandchildren. A recent multi-country study involving nine European countries, including Italy, has been published by Skopek (2021). Following an extensive review of the available evidence on the demography of grandparenthood, his paper presents demographic kinship models to explore changes in the demographic context of grand-motherhood and multigenerational women's relations in Europe, from the middle of the twentieth century to the present day. The author found that the age at which women experience grandparenthood has increased steadily in all countries over time, while population prevalence of grandparenthood has declined. Accordingly, the number of multigenerational family ties women experience in their lives has also decreased significantly over the past 60 years in Europe. In the country ranking proposed by Skopek, Spain and Italy stand out as having the lowest 'grandchild supply' (i.e., number of expected grandchildren over the life course), as well as the lowest prevalence of grand-motherhood. 
By using Italian data, Di Gessa, Bordone, and Arpino (2020) directly explore the link between fertility, measured as number of children and age at grandparenthood, and the transition to grandparenthood between and within 1920s, 1930s and 1940s birth cohorts. Their study clearly indicates a postponement in the timing of grandparenthood by cohorts. In the 20 years which separate men and women born in the 1920s and the 1940s, the estimated median age at grandparenthood moved forward by 5 years. Additionally, the authors provide evidence on the role of family composition and regional heterogeneity in this shift, suggesting that the overall postponement of median age is not uniform across different subgroups of mothers and fathers by number of children (with those having large and early families facing earlier transitions) and geographical area (driven by varying family compositions).

Broadly, though the demography of grandparents in Italy is a rather explored topic, at the current time there is almost no representative survey research that has addressed the question of how the transition to grandparenthood has been changing over time. Our paper investigates how falling mortality rates and delayed fertility have played out in Italy over the last two decades. Our aim is to participate in giving an overall understanding of the mid-term consequences of these changes on the demography of grandparenthood in Italy.

\section{Data and Methods}

\section{Data Sources}

Data for the analysis are drawn from two sources. First, to provide a comprehensive insight into the demographic profile of grandparents in Italy, we used data from the four waves of the Survey on Families, Famiglia e Soggetti Sociali (Family and Social Subjects - FSS), carried out by the Italian Institute of Statistics (ISTAT) in 1998, 2003, 2009 and 2016. The survey is the main statistical source on family structure and social characteristics of Italian households and covers a wide variety of information on contemporary and retrospective demographic and socio-economic characteristics for individuals resident in Italy (ISTAT, 2016). These data provide nationally representative estimates of the prevalence of grandparenthood among a large sample of adults and are representative of all persons aged 18 and over. The 
second data source is the Italian life tables by sex for 1998 and 2016 released by ISTAT, used to estimate the length of grandparenthood in the two years.

\section{Analytical sample}

The paper employs two different analytical samples. First, we include all respondents aged 35 and older, for which information on grandparenthood is available in the FSS Survey. By using this sample, we describe stability and changes in a set of demographic and socioeconomic characteristics on both grandparents' and non-grandparents' samples. Besides this, according to the approach of Margolis (2016), we work on breaking down the population into grandparents, non-grandparents because childless, non-grandparents because their children are childless. The focus is on assessing the population prevalence of the three groups and tracking changes from 1998 to 2016, the two extreme years of those available. Second, from the original sample we select respondents aged 60 and over at the time of interview with at least one living child in $1998(\mathrm{~N}=27.625)$ and $2016(\mathrm{~N}=15.743)$ to study the age at grandparenthood (sample selection reported in Table 4).

As fewer than $50 \%$ of the respondents are grandparents at young ages, we set the lower bound of age 60 to be able to estimate the median age at grandparenthood as a single measure of the distribution. Moreover, with a 60-year cut-off, we are accurate to assume that the first-order fertility process (i.e., grandparents' fertility) is mostly completed by all individuals in the risk set.

\section{Measures for the Demography of Grandparenthood}

Our main dependent variable is based on the self-reported grandparent status. It is recorded for respondents aged over 35 who are asked whether they had any grandchildren and, if so, how many grandchildren at the time of the survey. Those reporting at least one grandchild are coded as grandparents (1998: $\mathrm{N}=3.910 ; 2003: \mathrm{N}=4.119 ; 2009$ : $\mathrm{N}=3.855 ; 2016$ : $\mathrm{N}=2.627$ ), while respondents who are not grandparents are further allocated between those having children (i.e., their children are childless) and those who are childless. The few respondents who reported having grandchildren but no children were excluded from the sample (1998: $\mathrm{N}=60 ; 2003: \mathrm{N}=41 ; 2009: \mathrm{N}=16 ; 2016: \mathrm{N}=33$ ), while there is no missing data for the remaining sample. 
In all analysis, having children is coded in a broad way, including biological, adopted, or foster children. This is since the survey makes it unfeasible to reconstruct the direct kinship link between all reported children and grandchildren. Thus, if we had only focused on the biological children, we would not have known which and how many children are of their descent. Though, to test the robustness of this definition, we went through the trend in the share of adopted or fostered children in the four waves. The descriptive analyses reveal a consistent trend, so that the rate of adopted or fostered children in Italy remains firm at around $1 \%$ of the total number of children. Lastly, in addition to the prevalence of grandparenthood, we investigate age patterns, the number of grandchildren, the timing of the transition to grandparenthood and its duration.

Timing of grandparenthood (i.e., age at grandparenthood) is based on the date of birth of the first grandchild. Each grandparent in the FSS Survey is asked to list the age of up to three non-cohabiting grandchildren, while information on co-resident grandchildren is given in the household data sheet.

For respondents with no more than three grandchildren, the age at the first grandchild was figured as the difference between the age of the grandparent and the age of the oldest grandchild. Differently, for respondents with over three grandchildren, for whom we are not sure of their age at grandparenthood, we implement the strategy suggested by Di Gessa et al. (2020), who proved with a set of robustness tests the validity of their approach. For this subsample of grandparents, they consider as age at grandparenthood «the lowest age between (i) the age calculated by subtracting the age of the oldest grandchild among the three reported from the age of the respondent and (ii) the youngest age at which any of the respondent's children left home. In this latter case, we added 2 years assuming that respondents would become grandparents about 2 years after their child left the parental home».

We then further refined the last step of the estimating system as follows: (a) for those respondents whose child first left home born before 1960, we add 2 years to the age of the respondent, and 3 years in the case of male children who left before the age of 21 , to account 
for leaving home for military service ${ }^{1}$; (b) for those grandparents whose first child to leave home was born after 1960, we add 3 years to the respondents' age. These estimate adjustments let us account for the process of fertility postponement recorded in Italy in the 1935-70 generations (Caltabiano, Castiglioni, and Rosina 2009), approximately those of the children of the grandparents involved in the sub-sample (1998: GPs born before 1938; 2016 : GPs born before 1956).

Overall, the strong correlation explained by Di Gessa and colleagues between residential autonomy, marriage and fertility is still valuable, notably for the 1998 survey (Billari and Kohler 2002; Billari, Philipov, and Baizán 2001; Rosina and Fraboni 2004). For 2016, we can assume greater variability in the data, and thus a weaker association between these life events compared to previous data. Nevertheless, it is noteworthy that in the 2016 survey the share of grandparents aged over 60 with more than three grandchildren decreases (Table 4 ), so that the estimation system applies to a reduced number of observations. Besides, we test the correlation between the ages of grandparenthood calculated with the two methods for the sub-sample of grandparents for which we have the exact age at grandparenthood (i.e., grandparents of up to three grandchildren), and results confirm a strong correlation in 1998 $(r=0.70)$ and fairly strong in 2016 ( $r=0.57)$. Overall, the estimated age at grandparenthood is taken for $23 \%$ of grandparents in 1998 and for $16 \%$ of grandparents in 2016 . Lastly, to test the robustness of our findings, all analyses involving grandparenthood timing were replicated for the sample of grandparents for whom the event age is known, and these confirm the reported patterns (Table A.4 in the Appendix)

\section{Methodological approach}

After providing descriptive statistics for the four years of survey, we present the prevalence of grandparenthood by age and sex for 1998 and 2016 to capture possible variations over time. We then try to factorise the rest of the population into those who are not grandparents because they do not have children, and those who are not grandparents because their

\footnotetext{
${ }^{1}$ In 1998 each respondent reported on the sex of up to three children. When present (78\%), through the date of birth we linked it to the first child leaving the household. When absent, we assigned 2 years of time.
} 
children do not have children themselves. This, in turn, gives us the opportunity to estimate the relative contribution to the change in the prevalence of grandparents due to an increase in respondents' childlessness, or to their children's childlessness (Margolis 2016).

To describe the process of grandparenthood we follow the approach introduced by Leopold and Skopek (2015b). We use survival analysis to explore the median age at grandparenthood and other four life transitions: (1) transition to motherhood or fatherhood; (2) end of active parental status, which occurs when the youngest child turns 16; (3) transition to the empty nest, when all children leave the parental home; (4) age at retirement or transition to inactivity for those ever in paid work in the past. We use the retrospective event histories given by respondents to set the time axis to start in the respondent's year of birth and to end at the age at which each event occurs, as for example the age at birth of the first grandchild. If the year of one of the above transitions is not provided, the case is dropped from that particular analysis. Then we apply Kaplan-Meier estimates to compute the survival function

for each transition to assess the median age at each event (i.e., the $50^{\text {th }}$ percentile) and, in relation to grandparenthood, the probability of being a grandparent at different ages $(45,50$, $55,60,65,70$ ).

Models are performed separated by sex, in line with the different timing of major demographic events. However, to avoid large data amounts in the text and the occurrence of minor differences, the first descriptive section of the paper presents the results for the combined male and female sample. Details of data are nonetheless provided in the appendix (Tables from A.1 to A.3). Finally, given the descriptive nature of this article, for all analysis and descriptive tables we use normalized weights based on the population's marginal distribution coefficients provided by ISTAT.

\section{Results}

\section{Grandparents' demographic and socio-economic characteristics}

More than $30 \%$ of our samples had become grandparents. The proportion slightly differs among years (Table 1): around 33\% in 1998, 2003 and 2009, it fell to 31.5\% in 2016. In absolute values, there were about 10.9 million grandparents in Italy in 1998, 12.3 million in 2016 ; roughly $28 \%$ of men and $38 \%$ of women in $1998,27 \%$ and $35 \%$ each in 2016 . Overall, 
grandmothers represent the majority of respondents with a proportion still equal over time to about $60 \%$. Besides, the mean age of grandparents rose linearly from 68 years old in 1998 to nearly 71 in 2016.

\section{[Table 1 about here]}

Expected changes over time emerge in the proportion of married, separated or divorced, highly educated and foreign-born grandparents. As derived from table 1, these trends reflect more general changes involving the whole population aged over 35, including nongrandparents. However, the rate of increase of separated grandparents is higher than the that of non-grandparents (from 1.6\% in 1998 to 4\% in 2016 for grandparents; from 3.3\% to $6.6 \%$ among non-grandparents), as it is for the education level: in 1998, about 14\% of grandparents had an education beyond lower secondary school, this quota raised to 50\% after slightly less than 20 years. A major difference emerges between grandfathers and grandmothers regarding widowhood. Because of the male disadvantage in life expectancy, together with the fact that men are, on average, about three years older than the women they marry, the proportion of widows is generally four times as high as that of men, although it has decreased a little over time.

A distinctive trend is observed about work status. We find an increasing number of pensioners offset by a decreasing proportion of homemakers within grandparents, whereas employed and unemployed increase by under 1\%. In the non-grandparental population, meanwhile, the number of pensioners decreases, while employed and unemployed people rise. However, it is worth mentioning that the two groups are very dissimilar in terms of age and sex structure. Within non-grandparents the average age is around 50 to 52 years, and the gender composition is nearly equal. Besides, compared to the other variables described above, the trend in employment status is not linear over time and can be closely linked to the economic context of the observed year.

Fewer variations emerge across surveys when we consider the area of residence and the proportion of grandparents with their own income and home ownership (about $84 \%$ and $75 \%$ respectively). As regards the health status, unfortunately the questionnaire section changed over time and no measure is directly comparable. In 1998 and 2003 respondents were asked to report chronic diseases reducing their individual independence, while in 2009 
and 2016 they were asked to report the presence of any limitation in the daily activities caused by health problems. Although not comparable, these variables are found to have similar patterns, so we combined the information into one identifying those respondents reporting at least one limitation due to chronic diseases or health problems. Consistent with the health improvement we are aware of at a general population level, we find a positive health development between grandparents and non-grandparents over time.

\section{Grandparents' family and social network}

We also present descriptive statistics regarding the pattern of Italian grandparents' family and social networks over time. As expected, fertility postponement in Italy results in a declining mean number of children and grandchildren among grandparents (Table 2). The mean number of live born children for each respondent goes from 2.7 in 1998 to 2.4 in 2016, while the mean number of grandchildren from 3.5 to 3.1 respectively. Also, the prevalence of grandparents having no more than three grandchildren increases over time by 3 percentage points. Co-residence with children and grandchildren do not reveal a linear trend, while the share of grandparents living together with one parent decreases ${ }^{2}$. This, combined with the rising number of grandparents with at least one parent still alive, is consistent with the process of healthy ageing and increased longevity.

[Table 2 about here]

Finally, we turn to the presence and composition of kinship networks, friendship, and neighbourhood relations. This is due to the major role played by these networks as carriers of material and immaterial resources. Indeed, it is through the networks of relatives, friends, or other people whom one comes into contact that it is possible to receive, for example, practical or financial help, ask for emotional support, or access information that would otherwise be withheld.

From 1998 to 2016 there is a clear increase in the proportion of grandparents reporting to have friends and other relatives (besides close family members) they can count on in case of need: $36.7 \%$ in 1998 and $42.7 \%$ in 2016 report having friends, 30.4\% and 37.7\% (in 1998

\footnotetext{
${ }^{2}$ Information on parents is gathered only from respondents under 69 years old.
} 
and 2016 respectively) report having other relatives. In contrast, since 1998 the share of respondents who report they have neighbours they can count on decreases.

\section{Patterns in the prevalence of grandparenthood}

Figure 1 displays the proportion of people who have grandchildren during their lifetime, those who do not have grandchildren because they are childless or because their children are childless, by age and survey year. Overall, the median age at which half of the population over 35 is made up of grandparents moved forward by at least 5 years in the two observed decades. For both men and women, the postponement of grandparenthood is evident in middle age: the prevalence of grandfathers and grandmothers is reduced at any age in 2016 compared to 1998, and between the ages of 55 and 64 , the ratio significantly decreases by about 10 per cent.

Going into more detail, significant differences in the prevalence of grandmothers are observed after the age of 45 . As an example, in 1998 about $43 \%$ of women aged 55 to 59 had at least one grandchild, while this proportion fell to about 33\% in 2016. Relatedly, more than $60 \%$ of women aged between 60 to 64 were grandmothers in 1998, a share that goes down to about $50 \%$ in 2016. Men become grandparents later than women, and the first significant differences in their population prevalence are observed after the age of 50. Nevertheless, grand-fatherhood postponement is apparent. For example, the proportion of grandparents between the ages of 60 and 64 fell by around 11\% between 1998 and 2016, and by nearly $8 \%$ in the following age group.

[Figure 1 about here]

Figure 1 also shows the remaining share of respondents who are childless or their children are childless. Generally, the prevalence of childless and children-childless women and men decreases with age, but both significantly increased over time, contributing to the lower ratio of grandparents in middle age between 1998 and 2016. At younger ages the prevalence of childless interviewed in 2016 overtakes that of 1998. For women, we observe a reversal after 65 , when the prevalence of childless women is higher in 1998. This is offset by a higher prevalence of childless women and men in 2016, which exceeds 1998 after the age of 50 for the former, and after 55 for the latter. 
Thereafter, we factorise the contribution to the significant decrease of grandparents between the two time points in reduction due to lower grandparents' fertility (i.e. childless grandparents), and reduction due to lower grandparents' children's fertility (i.e. grandparents with childless children) (Table 3).

\section{[Table 3 about here]}

Among women, a significant decrease in the proportion of grandmothers is observed between the ages of 50 and 64. Among younger women, aged 50-54 we observe a decline in the prevalence of grandmothers by nearly $19 \% .73 \%$ of this difference is caused by increased grandmothers' childlessness, while $23 \%$ is attributable to the decline in children's childlessness. Among older women at ages 60-64, the most relevant factor which explains an $88 \%$ decline in the prevalence of grandmothers, is increased children's childlessness, while respondent's childlessness accounts for $12 \%$ of the gap. For men, statistically significant differences in the prevalence of grandparents can be noted until later ages. Nevertheless, from the causal breakdown we observe a similar trend as for women. At younger ages (5059) the minor proportion of grandparents in the population in 2016 compared to 1998 was mostly due to an increase in childlessness among those men, while after the age of 60 to an increase in their children's childlessness (above 85\%).

\section{The timing of the Transition to Grandparenthood}

Figure 2 presents the estimated median ages for mothers and fathers in 1998 to 2016. Survival analysis shows that the median age at grandparenthood moved ahead by 3 years over the last two decades. Generally, most men and women became grandparents in their late fifties, early sixties. Still, among mothers, the median age at grandparenthood rose from 54 in 1998 to 57 in 2016, and among fathers from 59 to 62.

[Figure 2 about here]

When comparing this figure with the simple mean age calculation (Table 4) we note a downward bias of 2 to 4 years due to right-censored observations. With grandparenthood postponement from 1998 to 2016, the gap between the two measures widens as the number of observations that are right-censored grow. So, the timing of grandparenthood shifts forward over the last two decades in Italy. Figure 3 shows some detailed findings in this 
respect. It reports the estimated probabilities of being a grandparent at different ages for the two years under observation, and clearly indicates the extent of grandparenthood postponement. More than $56 \%$ of fathers and $71 \%$ of mothers had become grandparents by the age of 60 in 1998. In 2016, this applied to less than $44 \%$ of fathers and $60 \%$ of mothers.

[Table 4 and Figure 3 about here]

On figure 2, in addition to the median age at grandparenthood, we could note another four life transitions of mothers and fathers on the same timelines: age at birth of the first child, age at end of active parental role (i.e., age at the youngest child's 16th birthday), age at empty nest (i.e., age at which all children leave the parental home) and age at retirement or inactivity. For this last transition, the risk set includes all individuals who have ever worked in the past. The retirement or economic inactivity event is considered to have occurred if the person retires or becomes unemployed, permanently sick or disabled, a homemaker, or no longer seeks work opportunities.

The sequences of the analysed life transitions are consistent across the two surveys for both men and women. Age at fatherhood was experienced at the median age of 29 in 1998 and of 28 in 2016, while motherhood started at age 25 and age 24 respectively. This is consistent with the U-shaped trend in fertility among the cohorts of grandparents in question. Indeed, the average age at childbirth in Italy has shifted from almost 29 years among women born in the early 1930 s to 27 years among the generations formed after the Second World War, then stabilized until the generations born in the mid-1950s. Keeping with this, the end of active parenting, so the age at which the youngest child turns 16, is also anticipated in the generation of grandparents aged over 60 in 2016 compared to those in 1998. It always precedes the birth of the first grandchild, while the empty-nest stage follows it. Instead, transition to retirement or other forms of work inactivity suggests some overlap with grandparenthood beginning and is stable between the two cohorts, at age 60 for fathers and 54 for mothers.

Finally, taking the difference between remaining life expectancy at age 60 and the median age at the transition to parenthood, we can provide a basic measure to estimate the expected length of grandparenthood in the studied population. We find that, although 
grandparenthood has been delayed, Italian grandparents can expect to live the same years of life shared with grandchildren both in 1998 and 2016: 21 years for fathers, 30 for mothers. Indeed, delayed grandparenthood ( +3 years) coincides with higher life expectancies at age 60 in 2016 than 1998 (84 for women and 80 for men in 1998, 87 and 83 respectively in 2016).

\section{Conclusion and discussion}

The present study aims to further the demographic understanding of Italian grandparenthood, providing a demographic profile of grandparenthood in Italy over the last twenty years, from 1998 to 2016, a period in which mortality declined, childlessness increased, and fertility was postponed. Even though a growing number of studies indicate that it is important to investigate the prevalence and timing of grandparenthood, few surveys collect data on the transition to grandparenthood (Hank et al. 2018). This study is the first applied to nationally representative survey data in Italy.

Generally, the profile of grandparents emerging from the FSS data is consistent with many of the trends noted in earlier research. According to expectation, results show a clear postponement of grandparenthood by age over time. Overall, the median age at which half of the population over 35 (for which we have information on grandparenthood in the questionnaire) is made up of grandparents, moved forward by at least 5 years during the two observed decades. The postponement of grandparenthood is evident in middle age: between 55 and 64 the ratio of grandparents to non-grandparents decreased significantly by about 10 per cent. Men become grandparents generally later than women, but postponement trends are detectable for both grandfathers and grandmothers.

In terms of timing and length of grandparenthood, results confirm that the extension of longevity enhance the duration of grandparenthood. Specifically, we found that although fertility trends have resulted in people becoming grandparents at older ages in 2016 than in 1998, large increases in life expectancy (about 3 years at age 60 for both men and women) outweighed the effect of this trend. Proportionally, that means that the stage of life in which grandparents and grandchildren are coexisting and can interact with each other is 
unchanged, according to the gender effects in longevity: relatively 21 years of expected life as grandfathers for men, and 30 expected as grandmothers for women. This notwithstanding the fact that, in terms of chronological age, on average grandparents are older today than in the past, partly due to falling numbers of children, and mostly due to the delay in the birth of grandchildren (i.e., deferred grandparents' children's fertility).

Additionally, our analysis suggests that increases in age of grandparenthood are larger than those in age at parenthood, age at retirement or inactivity in employment, age at end of active parenthood and at empty nest. Even though grandparents in 2016 live longer than in 1998, the intersection with other life events has not changed much. Supporting the findings of Leopold and Skopek (2015b) on other European countries, the end of active parenthood predates grandparenthood in Italy, while the empty-nest phase follows it. A minor change can be noted for retirement or inactivity, which, compared to 1998, precede grandparenthood by few years in 2016. This is a relevant point for individuals and societies, considering that the intersection of other life course transitions and the overlap of grandparenthood with other roles could create potential role conflicts (e.g., Arpino and Bordone 2017; Arpino and Gómez-León 2019; Van Bavel and De Winter 2013; Zanasi and Sieben 2020) and grandparents' embedding in a system of intergenerational relationships which include caregiving for grandchildren (e.g., Albertini and Tosi 2018; Arpino and Bordone 2014; Arpino, Pronzato, and Tavares 2013; Glaser and Hank 2018; Karen Glaser et al. 2013; Zamberletti et al. 2018).

In reference to the latter point, the changing profile of grandparenthood may also impact on the quality of intergenerational exchange. For example, if grandparents are having increasingly fewer grandchildren, they could potentially be more involved (both physically, financially and emotionally) with their grandchildren (Skopek 2021). Furthermore, becoming a grandparent later in life could affect how much people can actually do with their grandchildren. Despite being older, grandparents are expected to be healthier today than in the past. Indeed, the new generations of older people are different from the past, as rising levels of education and economic wellbeing, the adoption of healthier lifestyles, as well as medical prevention have had a large effect on the living conditions of the older population and on the quality of survival. The question is still open, and further research should examine 
whether physical and mental disability is being postponed at the same rate as grandparenthood in Europe.

The paper has some limitation, mostly concerning the implementation of survival methods and the cross-sectional nature of the FSS data. The main constraint is linked to the unavailability of data for the exact age at grandparenthood of the entire grandparents' sample. However, sensitivity analyses were carried out on the subgroup of respondents for which we do know the exact age at birth of the first grandchild (Table A.4 in the Appendix). Results confirm the emerged trends for which the end of active grandparenthood consistently precedes the birth of the first grandchild, while median age at empty nest follows. Median age at parenthood changes by one year in 1998 and for women in 2016, while age at retirement or employment inactivity clearly predates the age at arrival of the first grandchild in this model. This is particularly the case because we observe a shift by about 3 to 4 years in the median age at grandparenthood. The result is not unexpected, and still confirms our estimates to be robust. Indeed, by excluding from the sample of analysis those grandparents having more than three grandchildren we miss out the oldest respondents, who are most likely to have become grandparents at a younger age. This leads us to a slightly higher estimate of the median age at birth of the first grandchild.

A second limitation of our study is that our assessment of grandparenthood is limited to older adults, as the prevalence of grandparents is very low before age 60. Thus, we are not able to consider how fertility and mortality patterns shape the transition to grandparenthood of the more recent cohort of people. Is therefore unknown whether parents who are at risk of experiencing grandparenthood will become so in the future. Further, to define the risk set on which Kaplan-Meier estimates are based, we only consider parents in our models. Aware of the fact that a child must have reached reproductive age to conceive a child in turn, we performed some sensitivity analyses by excluding from the models those rare parents over 60 with children under 15 years old at the time of the survey. We found no significant differences in the results.

Finally, our period estimates of the Italian demography of grandparenthood offer a picture of two points in time, which is anyway useful when mortality has not yet been realized and 
cohort data are not available. However, one potential source of bias in this sense is selective mortality, or selective participation to the survey due to bad health conditions. Mortality and poor health attrition is of relevance if the process is related to fertility history (e.g., Grundy and Tomassini 2005) and cannot be controlled without longitudinal data. To partly control for this source of bias and to reduce the cohort's heterogeneity, we applied the same models to people aged 60-75. Even controlling for this restriction, our estimates are stable.

Despite these limitations, we believe that our findings are particularly useful for understanding the evolution of grandparenthood in Italy, and by the same time they constitute a benchmark for future comparisons. Nevertheless, they also highlight the need for further research, hinting at future directions. Certainly, an important objective for advanced research on the demography of grandparenthood is to capture its education gradient, while also accounting for cohort and regional differences. 
Table 1. Sample socio-economic and demographic characteristics by survey year and grandparental status. Weighted data, total sample.

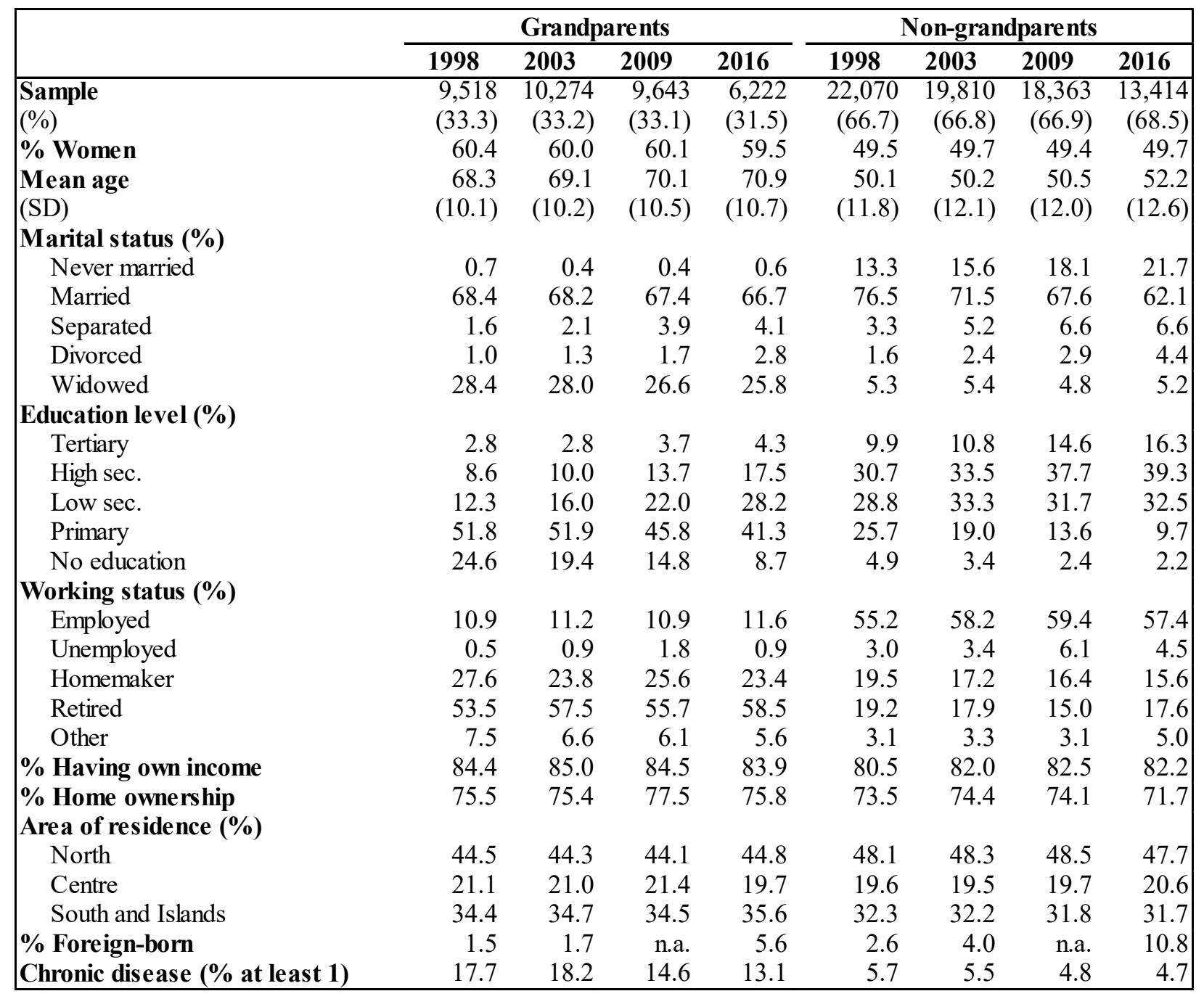

Source: Famiglie e Soggetti Sociali, ISTAT 
Table 2. Grandparents' (GPs) family and social network by year. Weighted data, total sample.

\begin{tabular}{|c|c|c|c|c|c|c|c|c|}
\hline \multirow[b]{3}{*}{ Mean number of children (SD) } & \multicolumn{8}{|c|}{ Survey year } \\
\hline & \multicolumn{2}{|c|}{1998} & \multicolumn{2}{|c|}{2003} & \multicolumn{2}{|c|}{2009} & \multicolumn{2}{|c|}{2016} \\
\hline & 2.7 & $(1.5)$ & 2.6 & $(1.4)$ & 2.5 & $(1.2)$ & 2.4 & $(1.1)$ \\
\hline Mean number of grandchildren (SD) & 3.5 & $(3.3)$ & 3.3 & $(2.9)$ & 3.2 & (2.6) & 3.1 & $(2.3)$ \\
\hline$\%$ Having up to 3 grandchildren & & 65.4 & & 65.9 & & 68.5 & & 68.4 \\
\hline$\%$ Co-residence with (at least) 1 grandchild & & 7.7 & & 7.1 & & 5.8 & & 7.6 \\
\hline$\%$ Co-residence with (at least) 1 child & & 39.9 & & 36.9 & & 31.5 & & 34.3 \\
\hline$\%$ At least 1 parent alive & & 27.7 & & 27.2 & & 31.1 & & 34.2 \\
\hline$\%$ Co-residence with at least 1 parent & & 7.4 & & 6.4 & & 5.9 & & 4.9 \\
\hline$\%$ Having neighbours to rely on & & 52.8 & & 48.8 & & 49.1 & & 48.8 \\
\hline$\%$ Having friends to rely on & & 38.5 & & 41.3 & & 44.6 & & 44.4 \\
\hline$\%$ Other relatives to rely on & & 30.3 & & 34.3 & & 35.0 & & 36.1 \\
\hline
\end{tabular}

Source: Famiglie e Soggetti Sociali, ISTAT

Note: ${ }^{\text {a }}$ Information gathered only from respondents under 69 years old. 
Figure 1. Prevalence of grandparenthood and factorisation of non-grandparental population by age, sex and year. Weighted data.

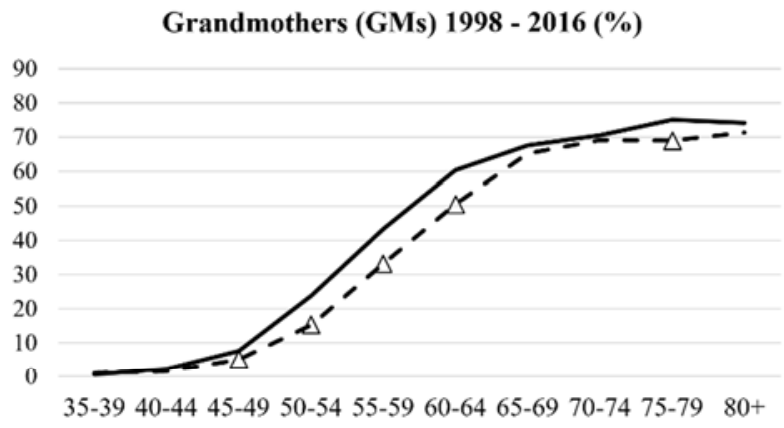

— GMs 1998 - - GMs 2016

Childless women 1998 - 2016 (\%)

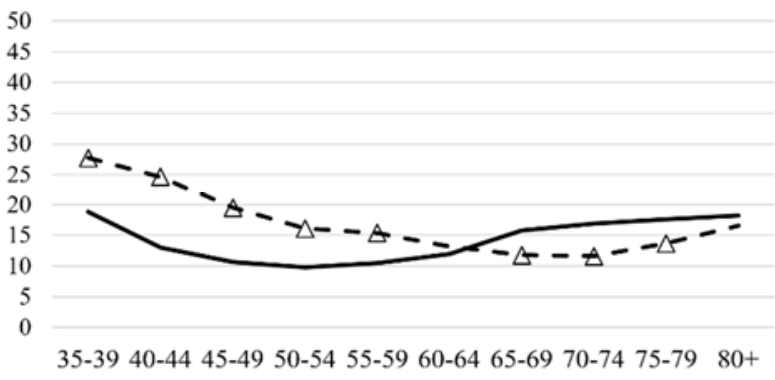

—W 1998 - - W 2016

Children childless women 1998 - 2016 (\%)

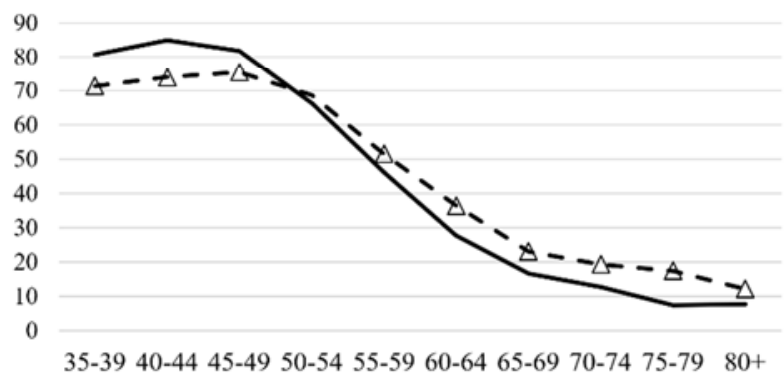

—W 1998 - - W 2016
Grandfathers (GFs) 1998 - 2016 (\%)

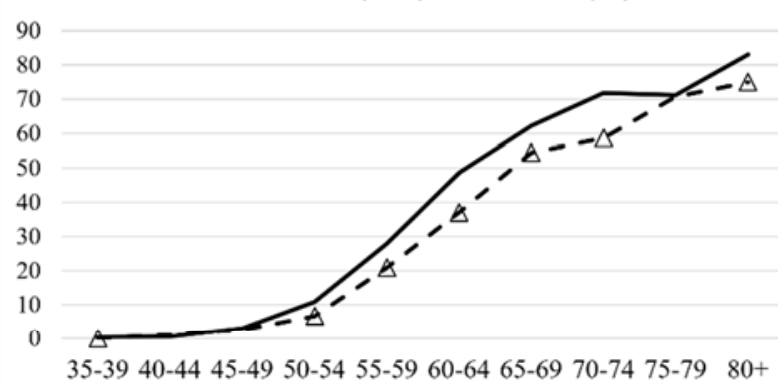

—GFs 1998 - - GFs 2016

Childless men 1998 - $2016(\%)$

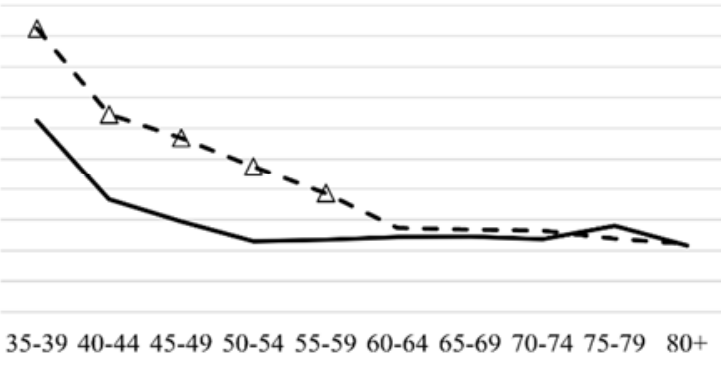

- M 1998 - $\mathrm{M} 2016$

Children childless men 1998 - 2016 (\%)

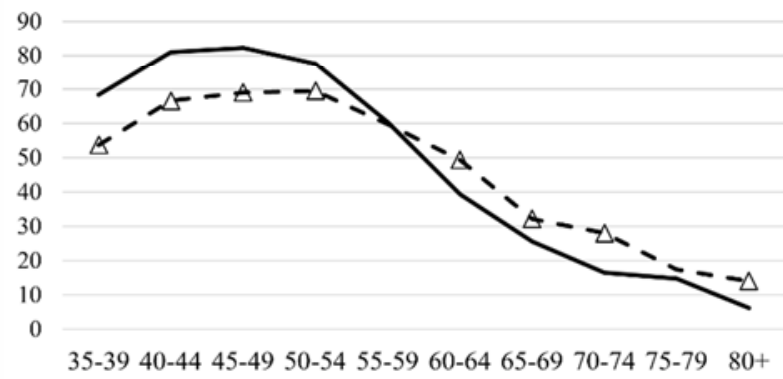

35-39 40-44 45-49 50-54 55-59 60-64 65-69 70-74 75-79 $80+$

Source: Famiglie e Soggetti Sociali, ISTAT.

Note: $\Delta \mathrm{p}<.05$ test for differences $1998-2016$ 
Table 3. Reasons for the declining prevalence of grandparents by age, sex and year.

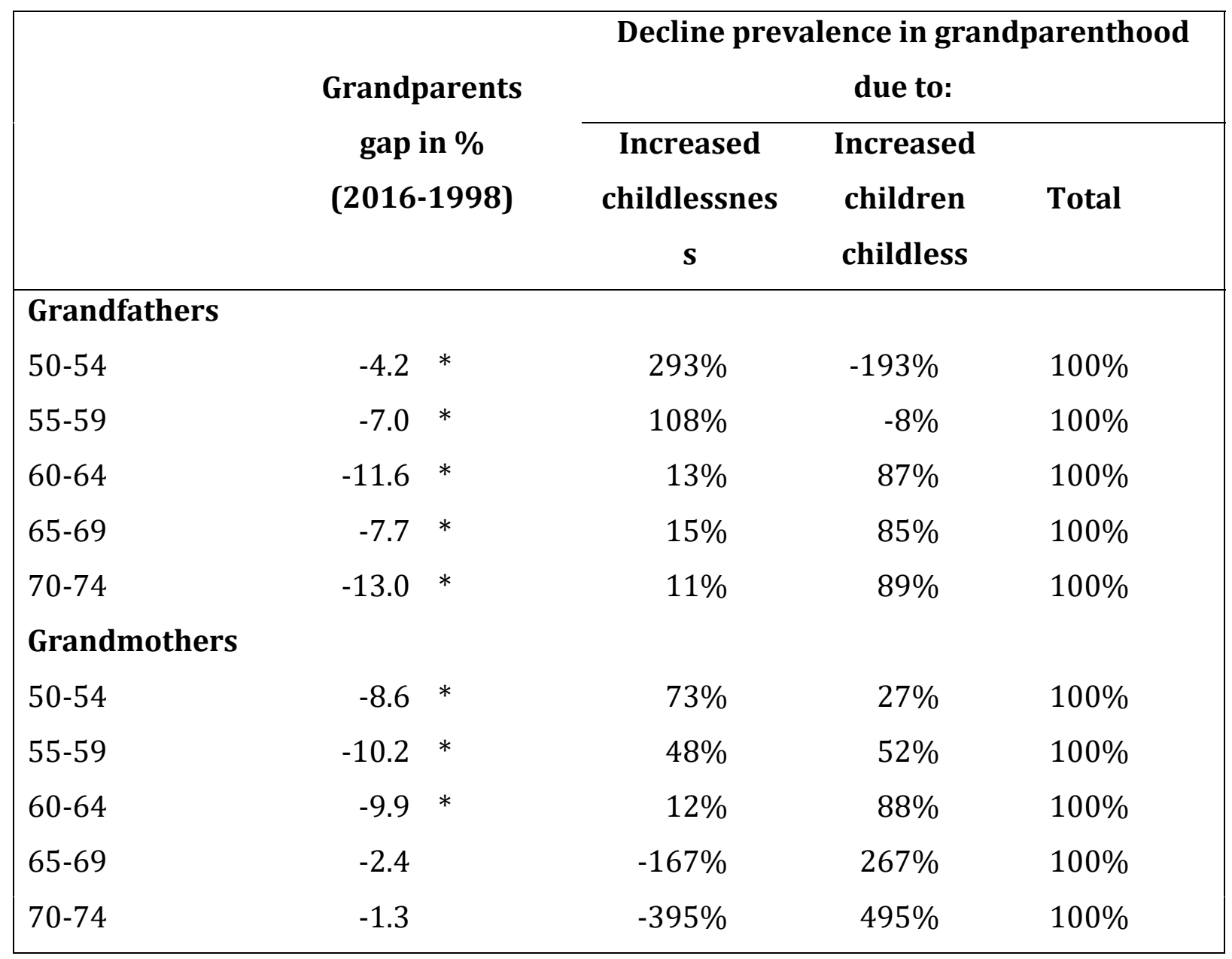

Source: Famiglie e Soggetti Sociali, ISTAT.

Note: ${ }^{*} \mathrm{p}<.05$ test for differences $1998-2016$ 
Table 4. Sample selection for survival analysis and descriptive statistics by year. Weighted proportions.

\begin{tabular}{|c|c|c|c|c|c|}
\hline & & \multicolumn{2}{|c|}{1998} & \multicolumn{2}{|c|}{2016} \\
\hline \multirow[t]{10}{*}{$\begin{array}{l}\text { Sample } \\
\text { selection }\end{array}$} & $\begin{array}{l}\text { Original sample } \\
\text { (of which) Parents } \\
\text { (of which) Aged over } 60\end{array}$ & & & & $\begin{array}{l}636 \\
743 \\
34\end{array}$ \\
\hline & Cohort range & \multicolumn{2}{|c|}{$1898-1938$} & \multicolumn{2}{|c|}{$1913-1956$} \\
\hline & Women (\%) & \multicolumn{2}{|c|}{56} & \multicolumn{2}{|c|}{55} \\
\hline & Grandparents (\%) & \multicolumn{2}{|c|}{78} & \multicolumn{2}{|c|}{71} \\
\hline & $\begin{array}{l}\text { Grandparents up to } 3 \text { grandchildren } \\
(\%)\end{array}$ & \multicolumn{2}{|c|}{60} & \multicolumn{2}{|c|}{65} \\
\hline & Mean age (SD) & \multicolumn{2}{|c|}{$71(7.8)$} & \multicolumn{2}{|c|}{$72(8.7)$} \\
\hline & & Men & Women & Men & Women \\
\hline & Mean n. of children & 2.4 & 2.5 & 2.1 & 2.3 \\
\hline & Mean n. of grandchildren & 3.5 & 4.1 & 3.1 & 3.4 \\
\hline & Mean age at grandparenthood (SD) & $\begin{array}{c}56 \\
(6.9)\end{array}$ & $52(6.9)$ & $\begin{array}{c}57 \\
(7.8)\end{array}$ & $53(8.3)$ \\
\hline
\end{tabular}


Figure 2. Timing of grandparenthood and other life transitions (median ages) by sex and year

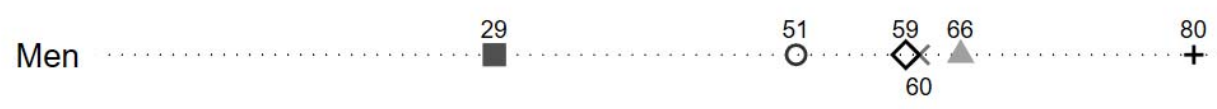

1998

Women

25

$\stackrel{4}{8}^{54} \ldots{ }^{63}$

$\stackrel{84}{+}$

Men

28

${ }_{0}^{49} \ldots \cdots \cdots x_{60}^{6265}$

$+83$

2016

Women

24

$\stackrel{46}{0} \cdots \times+{ }_{54}^{57}$

87

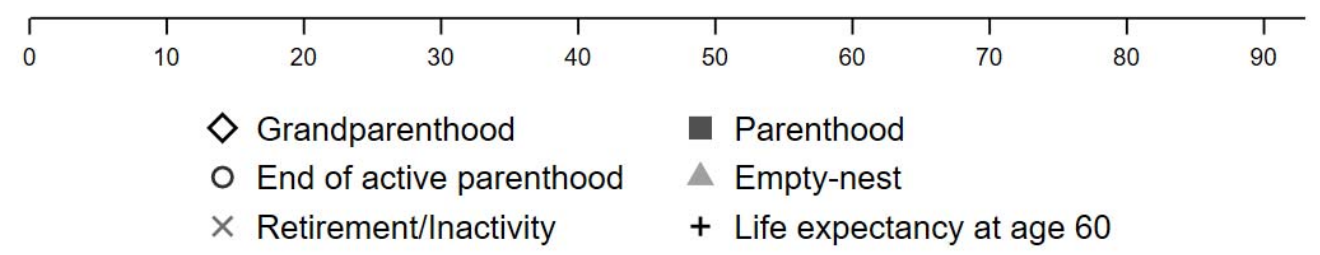

Source: Famiglie e Soggetti Sociali and Life Tables of the resident population, ISTAT.

Figure 3. Probability of becoming a grandparent by different ages, by sex and year.

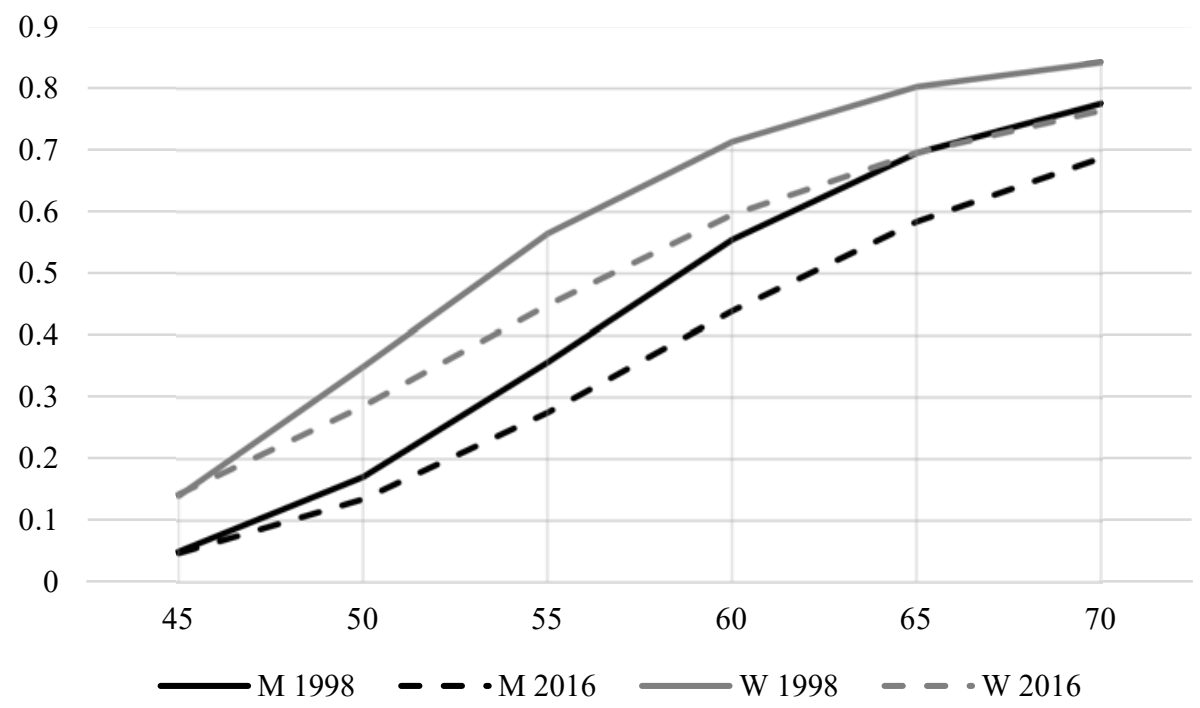


Appendix

Table A.1 Socio-economic and demographic characteristics by survey year and grandparental status. Weighted data, men.

\begin{tabular}{|c|c|c|c|c|c|c|c|c|}
\hline & \multicolumn{4}{|c|}{ Grandparents } & \multicolumn{4}{|c|}{ Non-grandparents } \\
\hline & 1998 & 2003 & 2009 & 2016 & 1998 & 2003 & 2009 & 2016 \\
\hline $\begin{array}{l}\text { Sample } \\
(\%)\end{array}$ & $\begin{array}{l}3,910 \\
(28.1)\end{array}$ & $\begin{array}{l}4,119 \\
(28.3)\end{array}$ & $\begin{array}{l}3,855 \\
(28.0)\end{array}$ & $\begin{array}{l}2,627 \\
(27.1)\end{array}$ & $\begin{array}{r}11,379 \\
(71.9)\end{array}$ & $\begin{array}{l}9,926 \\
(71.7)\end{array}$ & $\begin{array}{l}9,233 \\
(72.0)\end{array}$ & $\begin{array}{l}6,811 \\
(73.0)\end{array}$ \\
\hline $\begin{array}{l}\text { Mean age } \\
\text { (SD) }\end{array}$ & $\begin{array}{l}68.3 \\
(9.2)\end{array}$ & $\begin{array}{l}69.3 \\
(9.5)\end{array}$ & $\begin{array}{l}70.3 \\
(9.8)\end{array}$ & $\begin{array}{r}71.2 \\
(10.0)\end{array}$ & $\begin{array}{r}49.6 \\
(11.0)\end{array}$ & $\begin{array}{r}49.8 \\
(11.3)\end{array}$ & $\begin{array}{r}50.3 \\
(11.3)\end{array}$ & $\begin{array}{r}51.9 \\
(11.9)\end{array}$ \\
\hline \multicolumn{9}{|l|}{ Marital status (\%) } \\
\hline Never married & 0.4 & 0.2 & 0.2 & 0.3 & 13.6 & 16.7 & 20.3 & 24.2 \\
\hline Married & 86.8 & 85.3 & 84.4 & 82.6 & 80.1 & 74.4 & 69.5 & 63.0 \\
\hline Separated & 1.7 & 2.1 & 3.8 & 4.3 & 3.0 & 5.1 & 6.2 & 6.8 \\
\hline Divorced & 0.6 & 1.1 & 1.4 & 2.6 & 1.4 & 1.9 & 2.3 & 3.9 \\
\hline Widowed & 10.5 & 11.3 & 10.2 & 10.2 & 1.9 & 1.9 & 1.6 & 2.1 \\
\hline \multicolumn{9}{|l|}{ Education level (\%) } \\
\hline Tertiary & 4.2 & 3.9 & 5.1 & 4.7 & 10.7 & 11.0 & 13.5 & 15.2 \\
\hline High sec. & 10.7 & 12.1 & 17.0 & 20.3 & 32.1 & 33.6 & 38.0 & 39.2 \\
\hline Low sec. & 15.3 & 19.0 & 26.3 & 32.3 & 31.1 & 35.8 & 34.5 & 35.4 \\
\hline Primary & 51.7 & 50.7 & 41.3 & 37.1 & 22.7 & 17.2 & 12.3 & 8.5 \\
\hline No education & 18.2 & 14.3 & 10.3 & 5.6 & 3.4 & 2.4 & 1.7 & 1.7 \\
\hline \multicolumn{9}{|l|}{ Working status (\%) } \\
\hline Employed & 18.1 & 16.2 & 17.1 & 15.2 & 71.3 & 72.0 & 73.0 & 67.6 \\
\hline Unemployed & 0.9 & 1.6 & 2.2 & 1.4 & 3.8 & 4.0 & 6.3 & 5.5 \\
\hline Homemaker & n.a. & n.a. & n.a. & 0.8 & n.a. & n.a. & n.a. & 0.5 \\
\hline Retired & 76.6 & 78.3 & 75.8 & 77.6 & 21.7 & 20.9 & 17.6 & 20.0 \\
\hline Other & 4.3 & 3.9 & 5.0 & 5.1 & 3.2 & 3.2 & 3.1 & 6.4 \\
\hline$\%$ Having own income & 98.7 & 98.5 & 97.9 & 97.8 & 96.4 & 96.7 & 95.2 & 93.7 \\
\hline \multicolumn{9}{|l|}{ Area of residence $(\%)$} \\
\hline North & 43.0 & 42.9 & 43.6 & 44.9 & 48.2 & 48.8 & 49.0 & 47.8 \\
\hline Centre & 21.4 & 20.8 & 21.1 & 18.6 & 19.6 & 19.3 & 19.7 & 20.7 \\
\hline South and Islands & 35.6 & 36.3 & 35.4 & 36.5 & 32.2 & 31.9 & 31.4 & 31.5 \\
\hline$\%$ Home ownership & 78.3 & 77.9 & 79.7 & 76.1 & 73.3 & 74.2 & 74.2 & 71.6 \\
\hline$\%$ Foreign-born & 1.2 & 1.2 & n.a. & 4.6 & 2.0 & 3.6 & n.a. & 9.5 \\
\hline Chronic disease (\% at least 1 . & 15.2 & 16.0 & 13.2 & 12.0 & 4.6 & 4.5 & 4.5 & 4.3 \\
\hline
\end{tabular}

Source: Famiglie e Soggetti Sociali, ISTAT

Note: n.a. not available information 
Table A.2 Socio-economic and demographic characteristics by survey year and grandparental status. Weighted data, women.

\begin{tabular}{|c|c|c|c|c|c|c|c|c|}
\hline & \multicolumn{4}{|c|}{ Grandparents } & \multicolumn{4}{|c|}{ Non-grandparents } \\
\hline & 1998 & 2003 & 2009 & 2016 & 1998 & 2003 & 2009 & 2016 \\
\hline Sample & 5,608 & 6,155 & 5,788 & 3,595 & 10,691 & 9,884 & 9,130 & 6,603 \\
\hline$(\%)$ & $(37.9)$ & $(37.5)$ & $(37.5)$ & $(35.5)$ & $(62.1)$ & $(62.5)$ & $(62.5)$ & $(64.5)$ \\
\hline Mean age & 68.3 & 68.9 & 70.1 & 70.7 & 50.6 & 50.6 & 50.7 & 52.5 \\
\hline (SD) & $(10.7)$ & $(10.7)$ & $(10.9)$ & (11.1) & $(12.6)$ & $(12.8)$ & $(12.7)$ & $(13.2)$ \\
\hline \multicolumn{9}{|l|}{ Marital status (\%) } \\
\hline Never married & 1.0 & 0.5 & 0.6 & 0.9 & 13.0 & 14.5 & 15.8 & 19.1 \\
\hline Married & 56.3 & 56.8 & 56.0 & 55.8 & 72.7 & 68.6 & 65.6 & 61.2 \\
\hline Separated & 1.4 & 2.1 & 4.0 & 4.0 & 3.6 & 5.3 & 7.0 & 6.4 \\
\hline Divorced & 1.3 & 1.5 & 1.9 & 2.9 & 1.8 & 2.9 & 3.5 & 5.0 \\
\hline Widowed & 40.1 & 39.2 & 37.5 & 36.4 & 8.9 & 8.8 & 8.1 & 8.3 \\
\hline \multicolumn{9}{|l|}{ Education level (\%) } \\
\hline Tertiary & 1.8 & 2.0 & 2.7 & 4.1 & 9.0 & 10.6 & 15.7 & 17.4 \\
\hline High sec. & 7.2 & 8.7 & 11.6 & 15.5 & 29.3 & 33.5 & 37.4 & 39.4 \\
\hline Low sec. & 10.3 & 13.9 & 19.1 & 25.5 & 26.5 & 30.8 & 28.8 & 29.6 \\
\hline Primary & 51.9 & 52.6 & 48.8 & 44.2 & 28.7 & 20.8 & 14.9 & 11.0 \\
\hline No education & 28.8 & 22.8 & 17.9 & 10.8 & 6.5 & 4.4 & 3.2 & 2.6 \\
\hline \multicolumn{9}{|l|}{ Working status (\%) } \\
\hline Employed & 6.2 & 7.9 & 6.8 & 9.2 & 38.8 & 44.2 & 45.5 & 47.0 \\
\hline Unemployed & 0.2 & 0.5 & 1.5 & 0.6 & 2.2 & 2.8 & 5.9 & 3.4 \\
\hline Homemaker & 45.7 & 39.6 & 42.6 & 38.8 & 39.3 & 34.6 & 33.1 & 30.9 \\
\hline Retired & 38.3 & 43.6 & 42.4 & 45.5 & 16.6 & 14.9 & 12.3 & 15.1 \\
\hline Other & 9.7 & 8.4 & 6.8 & 5.9 & 3.1 & 3.5 & 3.1 & 3.6 \\
\hline \% Having own income & 75.0 & 76.1 & 75.6 & 74.5 & 64.1 & 67.3 & 69.4 & 70.6 \\
\hline \multicolumn{9}{|l|}{ Area of residence $(\%)$} \\
\hline North & 45.5 & 45.2 & 44.5 & 44.7 & 48.0 & 47.8 & 48.0 & 47.6 \\
\hline Centre & 20.9 & 21.1 & 21.6 & 20.4 & 19.7 & 19.7 & 19.7 & 20.5 \\
\hline South and Islands & 33.5 & 33.7 & 33.9 & 34.9 & 32.4 & 32.6 & 32.3 & 31.9 \\
\hline \% Home owners hip & 73.6 & 73.7 & 76.1 & 74.8 & 73.7 & 74.5 & 73.9 & 71.8 \\
\hline$\%$ Foreign-born & 1.7 & 2.0 & n.a. & 6.2 & 3.2 & 4.3 & n.a. & 12.1 \\
\hline Chronic disease (\% at least 1 . & 19.4 & 16.7 & 15.6 & 13.8 & 6.8 & 6.4 & 5.1 & 5.1 \\
\hline
\end{tabular}

Source: Famiglie e Soggetti Sociali, ISTAT

Note: n.a. not available information 
Table A.3 Grandmothers' and grandfathers' family and social network by year. Weighted data.

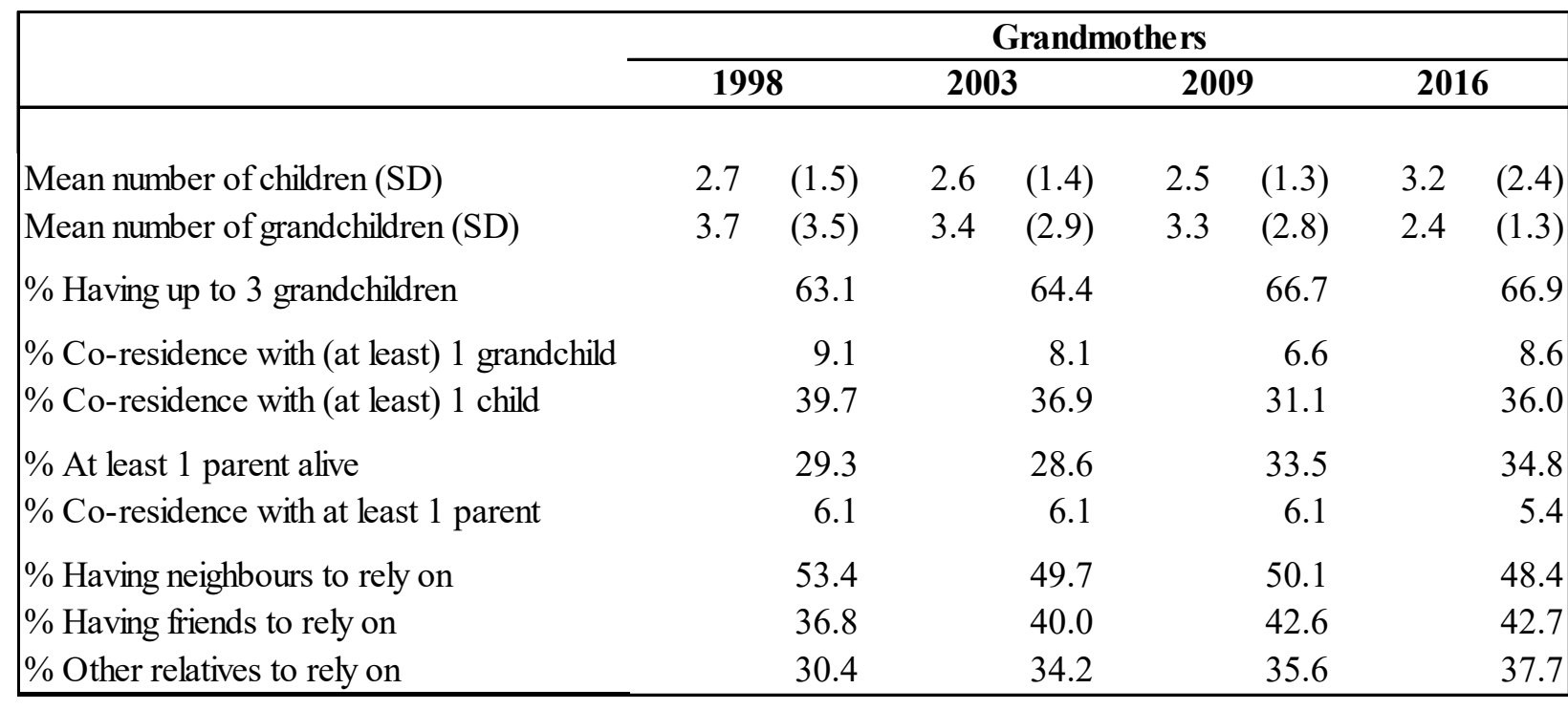

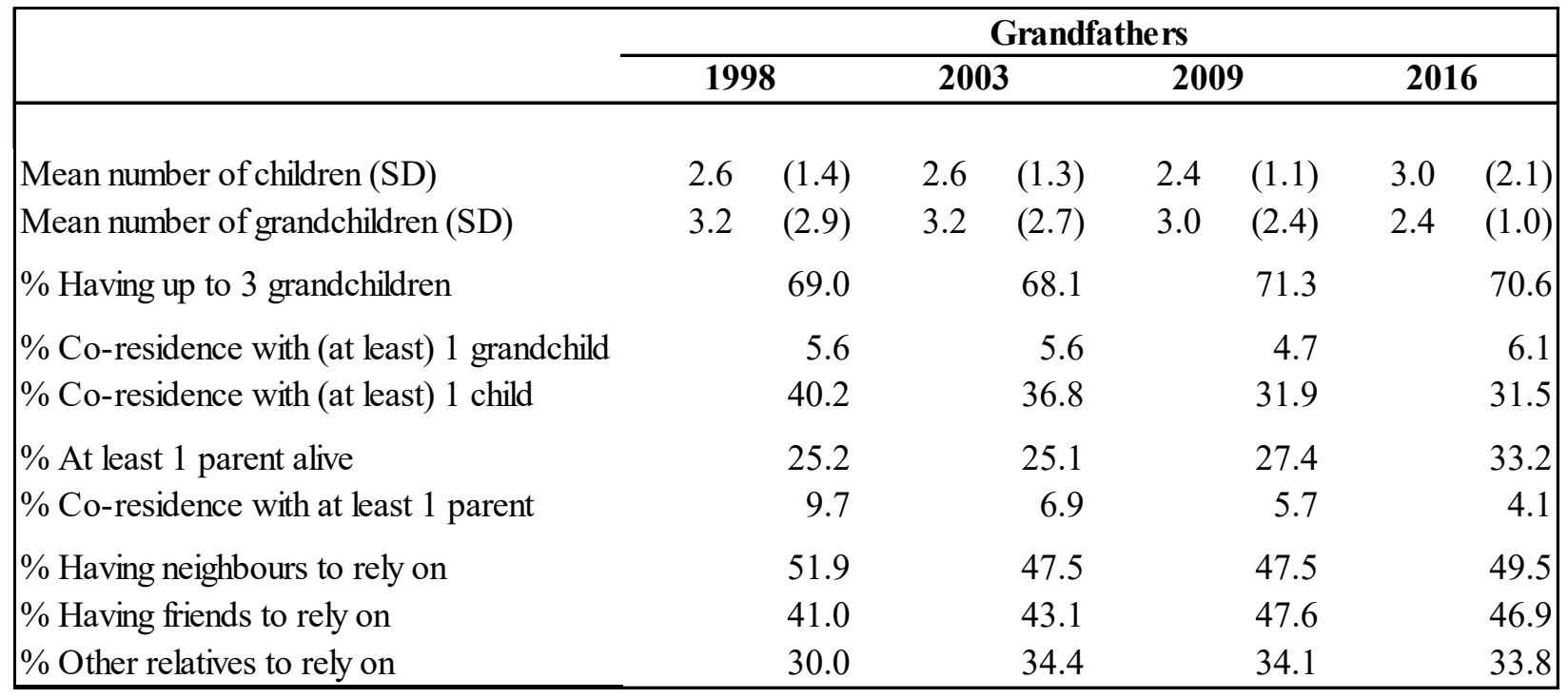

Source: Famiglie e Soggetti Sociali, ISTAT 
Table A.4 Transitional probabilities to grandparenthood, median age of grandparenthood and other life transitions by sex and year. Grandparents with no more than 3 grandchildren.

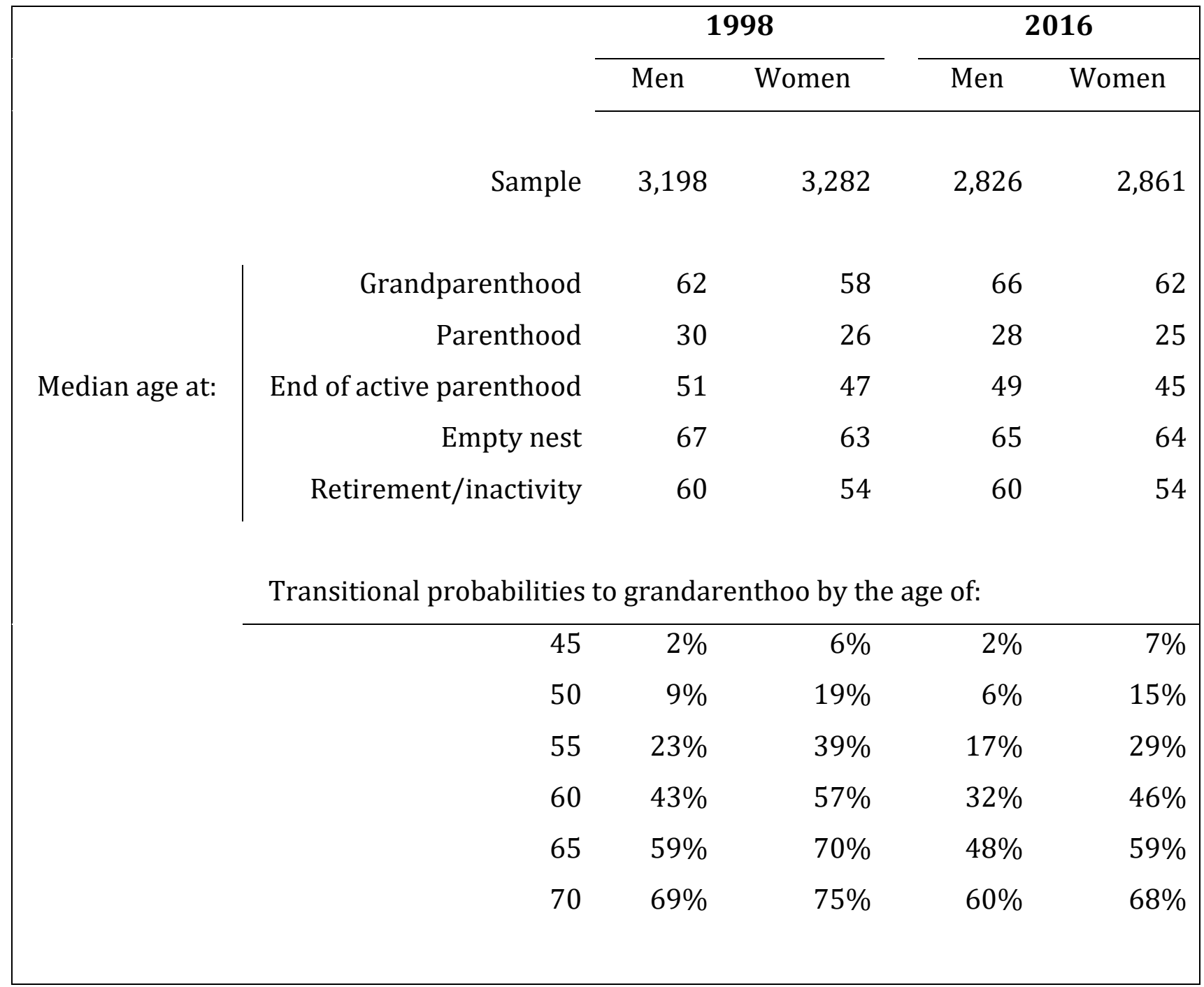

Source: Famiglie e Soggetti Sociali, ISTAT 


\section{References}

Albertini, Marco and Marco Tosi. 2018. "Grandparenting after Parental Divorce: The Association between Non-Resident Parent-Child Meetings and Grandparenting in Italy." European Journal of Ageing 15:277-86.

Arpino, Bruno and Valeria Bordone. 2014. "Does Grandparenting Pay off? The Effect of Child Care on Grandparents' Cognitive Functioning." Journal of Marriage and Family 76(2):337-51.

Arpino, Bruno and Valeria Bordone. 2017. "Regular Provision of Grandchild Care and Participation in Social Activities." Review of Economics of the Household 15:135-74.

Arpino, Bruno and Madelin Gómez-León. 2019. "Consequences on Depression of Combining Grandparental Childcare with Other Caregiving Roles.” Aging \& Mental Health 24(8):1263-70.

Arpino, Bruno, Chiara Pronzato, and Lara Patrrcio Tavares. 2013. "Mothers' Labour Market Participation: Do Grandparents Make It Easier?” SSRN Electronic Journal (7065).

Van Bavel, J. and T. De Winter. 2013. "Becoming a Grandparent and Early Retirement in Europe." European Sociological Review 29(6):1295-1308.

Bengtson, VL. 2001. “The Burgess Award Lecture: Beyond the Nuclear Family: The Increasing Importance of Multigenerational Bonds." Journal of Marriage and Family 63(1):1-16.

Billari, F. and H. P. Kohler. 2002. "The Impact of Union Formation Dynamics on First Births in West Germany and Italy: Are There Signs of Convergence." Pp. 43-58 in Dynamics of fertility and partnership in Europe: Insights and lessons from comparative research, edited by K. E. . C. M. Geneva/New York: United Nations.

Billari, Francesco C., Dimiter Philipov, and Pau Baizán. 2001. “Leaving Home in Europe: The Experience of Cohorts Born around 1960." International Journal of Population Geography 7(5):339-56.

Caltabiano, Marcantonio, Maria Castiglioni, and Alessandro Rosina. 2009. "Lowest-Low Fertility: Signs of a Recovery in Italy?" Demographic Research 21:681-718.

Chapman, Simon N., Mirkka Lahdenperä, Jenni E. Pettay, and Virpi Lummaa. 2017. “Changes in Length of Grandparenthood in Finland 1790-1959." Finnish Yearbook of Population Research 52:3-13.

Dykstra, PA and AE Komter. 2006. "Structural Characteristicsf Dutch Kin Networks.” Pp. 2142 in Family Solidarity in the Netherlands, edited by P. Dykstra, M. Kalmijn, T. Knijn, A. Komter, A. Liefbroer, and C. Mulder. Amsterdam: Dutch University Press.

Di Gessa, Giorgio, Valeria Bordone, and Bruno Arpino. 2020. "The Role of Fertility in the Demography of Grandparenthood: Evidence from Italy." Journal of Population Ageing.

Glaser, K., Debora Price, Giorgio Di Gessa, Eloi Ribe, Rachel Stuchbury, and Anthea Tinker Karen Glaser. 2013. “Grandparenting in Europe: Family Policy and Grandparents' Role in Providing Childcare." Grandparents Plus.

Glaser, Karen and Karsten Hank. 2018. "Grandparenthood in Europe." European Journal of Ageing 15:221-23.

Goodman, Leo A., Nathan Keyfitz, and Thomas W. Pullum. 1974. "Family Formation and the Frequency of Various Kinship Relationships." Theoretical Population Biology 5(1):1-27. 
Grundy, Emily and Cecilia Tomassini. 2005. "Fertility History and Health in Later Life: A Record Linkage Study in England and Wales." Social Science \& Medicine 61:217-28.

Hank, Karsten, Giulia Cavrini, Giorgio Di Gessa, and Cecilia Tomassini. 2018. "What Do We Know about Grandparents? Insights from Current Quantitative Data and Identification of Future Data Needs." European Journal of Ageing 15(3):225-35.

ISTAT. 2021. "Demo-Geodemo. Maps, Population, Demography of ISTAT - Italian Institute of Statistics." Retrieved September 26, 2021 (http://demo.istat.it/index_e.php).

Kemp, Candace L. 2003. "The Social and Demographic Contours of Contemporary Grandparenthood: Mapping Patterns in Canada and the United States." Journal of Comparative Studies 34(2):187-212.

Leopold, Thomas and Jan Skopek. 2015a. "The Delay of Grandparenthood: A Cohort Comparison in East and West Germany." Journal of Marriage and Family 77(2):441-60.

Leopold, Thomas and Jan Skopek. 2015b. "The Demography of Grandparenthood: An International Profile." Social Forces 94(2):801-32.

Lesthaeghe, Ron. 2010. "The Unfolding Story of the Second Demographic Transition." Population and Development Review 36(2):211-51.

Margolis, Rachel. 2016. "The Changing Demography of Grandparenthood." Journal of Marriage and Family 78(3):610-22.

Margolis, Rachel and Natalie Iciaszczyk. 2015. "The Changing Health of Canadian Grandparents." Canadian Studies in Population 42(4):63-76.

Margolis, Rachel and Ashton M. Verdery. 2019. "A Cohort Perspective on the Demography of Grandparenthood: Past, Present, and Future Changes in Race and Sex Disparities in the United States." Demography 56(4):1495-1518.

Margolis, Rachel and Laura Wright. 2017. "Healthy Grandparenthood: How Long Is It, and How Has It Changed?" Demography 54:2073-99.

Rosina, Alessandro and Romina Fraboni. 2004. "Is Marriage Losing Its Centrality in Italy?" Demographic Research 11:149-72.

Silverstein, M., R. Giarrusso, and V. Bengtson. 1998. "Intergenerational Solidarity and the Grandparent Role." Pp. 144-58 in The handbook on grandparenthood, edited by M. Szinovacz. Connecticut: Greenwood Press.

Skopek, Jan. 2021. "Grandparent Status and Multigenerational Relationships." Pp. 278-99 in Research Handbook on the Sociology of the Family. Edward Elgar Publishing.

Skopek, Jan and Thomas Leopold. 2017. "Who Becomes a Grandparent-and When? Educational Differences in the Chances and Timing of Grandparenthood." Demographic Research 37(29):917-28.

Song, Xi and Robert D. Mare. 2019. "Shared Lifetimes, Multigenerational Exposure, and Educational Mobility." Demogrpahy 56(3):891-916.

Szinovacz, Maximiliane E. 1998. "Grandparents Today: A Demographic Profile." Gerontologist 38(1):37-52.

Uhlenberg, Peter. 1993. "Demographic Change and Kin Relationships in Later Life." Annual Review of Gerontology and Geriatrics 13(1):219-38.

Zamberletti, Jessica, Giulia Cavrini, and Cecilia Tomassini. 2018. "Grandparents Providing 
Childcare in Italy." European Journal of Ageing 15:265-75.

Zanasi, Francesca and Inge Sieben. 2020. “Grandmothers' Transition to Retirement: Evidence from Italy." Polis (Italy) 34(2):281-308.

Zanatta, Anna Laura. 2013. I Nuovi Nonni. Una Risorsa Cruciale per Le Famiglie Di Oggi - Anna Laura Zanatta - Libro - Il Mulino - Farsi Un'ídea / IBS. Bologna: Il Mulino. 